\title{
BMJ Open Work-related injuries resulting in death in Chile: a cross-sectional study on 2014 and 2015 registries
}

\author{
Vivienne C Bachelet ${ }^{1,2}$
}

This article has received a badge for Open data.

To cite: Bachelet VC. Workrelated injuries resulting in death in Chile: a crosssectional study on 2014 and 2015 registries. BMJ Open 2018;8:e20393. doi:10.1136/ bmjopen-2017-020393

- Prepublication history for this paper is available online. To view these files, please visit the journal online (http://dx.doi. org/10.1136/bmjopen-2017020393).

Received 1 November 2017 Revised 12 April 2018 Accepted 4 May 2018
Check for updates

${ }^{1}$ Facultad de Ciencias Médicas, Universidad de Santiago de Chile, Santiago, Chile

${ }^{2}$ Medwave Estudios Limitada, Santiago, Chile

Correspondence to Dr Vivienne C Bachelet; vivienne.bachelet@usach.cl

\section{ABSTRACT}

Objective To characterise work-related fatal events that occurred in Chile in 2014 and 2015 in workers covered by the Occupational Accidents and Professional Disease No 16.744 Act.

Design Cross-sectional on registries of the Chilean Worker's Health and Safety National Information System, specifically focusing on the Fatal Work Accidents Registry of the Social Security Superintendence.

Study population Secondary data analysis on all 815 cases of occupational injury-related deaths registered in 2014 and 2015 in Chile and that were accredited by the Social Security Superintendence up to March 2016. Outcome measures Variables relating to employer, workers and the events were analysed.

Results The overall mortality rate for all injuries, both at work and during commuting, per 100000 workers affiliated to the occupational social security system, was 7.2 for 2014 and 7.3 for 2015. For 2014, the highest mortality rates occurred in the transport and communications sectors (20.15) and the mining sector (18.17), while for 2015 the highest rates were found in the fishing industry (11.3) and in mining (12.1). Seventy-two per cent of cases occurred in small and medium-sized enterprises. Half of the companies that had work-related fatal injuries did not have a risk prevention department. Twenty-two per cent (121) of the companies had previous labour law infractions. The four activities most affected by workers' deaths in the two study years were freight land transport, engineering works under construction, minor works under construction and construction of complete buildings or parts of buildings. Half of all fatal injuries occurred in workers who had been employed for less than a year in their company.

Conclusions This descriptive study provides valuable insight into the current national registry on occupational deaths in Chile. While containing valuable information, the registry was not designed for epidemiological surveillance. Further efforts are needed to achieve a proper epidemiological integration of surveillance data.

\section{INTRODUCTION}

Each year, serious and fatal occupational injuries occur in Chile and globally. The International Labour Organization has stated that 2.78 million workers die each year from work-related injuries and illnesses. ${ }^{1}$ The global economic impact has been estimated

\section{Strengths and limitations of this study}

First and only study conducted in Chile on the national registry of work-related deaths.

- Mortality rates for fatal occupational injuries are provided, for the first time including deaths commuting to and from work.

- The registry is driven by administrative needs and was not designed for epidemiological surveillance.

to account for approximately $3.94 \%$ of global gross domestic product each year. ${ }^{2}$ Governments and social security systems are responsible for preventing this human suffering that affects people during their productive life, the impact of which is carried over to families and loved ones. ${ }^{1}$ The introductory session of the fifth World Congress on Occupational Safety and Health in 1999 underscored the need to improve policies and legislation, including the implementation of better recording and notification systems, among other important policy measures. ${ }^{3}$ Despite the impact on the health and lives of workers arising from preventable occupational hazards, Chile still has not ratified the 1981 No 155 Occupational Safety and Health Convention. $^{4}$

In Chile, the 16.744 National Act on Work-related Accidents and Professional Diseases enacted on 1 February 1968 created the mandatory and universal occupational social security insurance system to provide healthcare and economic compensations to workers who suffer a work-related injury or who develop a professional disease, as well as to set up preventive programmes in the workplace. The system covers all employees, self-employed workers, students who are generating income for their institutions through their work and union leaders exercising their functions. ${ }^{5}$ The insurance is effective from the first day on the job and covers injuries that occur at the workplace and during commuting. The law defines a 
work-related injury as that caused directly or indirectly by workplace activities. Injuries arising from natural disasters are not covered by this social security scheme and instead must be dealt with by the national healthcare systems, either public or private. Military personnel and the armed forces are not covered as they have a separate system. ${ }^{6}$

The administration system is made up of one public entity and three private not-for-profit entities. All four entities are legally mandated to develop and implement programmes to prevent work-related hazards, and to provide health prevention services and treatment of occupational injuries and professional diseases. In 2014, there were 5594519 workers protected under the Act, ${ }^{7}$ while in 2015, the population of affiliated workers was $5647982 .^{8}$ The World Bank reports that in 2017 Chile had a total labour force of roughly under 9 million, ${ }^{9}$ the difference being accounted for by informal jobs that are not covered by the worker's occupational safety insurance system. In 2013 , the unprotected workforce was estimated at $28.7 \%$ of the total workforce. ${ }^{10}$

Chile lacks epidemiological studies on fatal work-related injuries, a prevalent problem in low/middle-income countries. ${ }^{11}$ Policymakers and the entities that administer the occupational health and safety insurance scheme are legally mandated to develop preventive strategies to reduce the rates of mortality and disability arising from injuries in the workplace or commuting to and from work. To this effect, there is a need for studies that shed light on the intervening factors and to develop an evidence basis to inform preventive strategies. The purpose of this study, which was specifically commissioned by one of the occupational insurance entities, is to characterise fatal occupational injuries occurring in Chile in workers protected by the 16.744 Act, using the mandatory registration systems of the Social Security Superintendence for the period 2014 and 2015 as data source.

\section{METHODS}

\section{Design}

A cross-sectional study analysing secondary data from registries of the National Occupational Health and Safety Information System (SISESAT, Sistema Nacional de Información de Seguridad y Salud en el Trabajo) for 2014 and 2015 under the purview of the Social Security Superintendence.

\section{Setting and participants}

All injuries with a fatal outcome affecting workers and confirmed by the Superintendence of Social Security as work-related by 24 March 2016 were included for the 2 years covered by the study. Each worker insurance entity must classify injuries as occupational or not after conducting an administrative check that relies on different sources, including health authority enquiries, clinical records, witnesses, and so on. After this due diligence, the Superintendence officially confirms the occupational origin of fatal injuries.
Chilean legislation defines a work-related 'accident' (this is the term used in all of the Chilean official documents) in article No 5 of Act 16.744 as any injury that a person suffers caused by or in occasion of work, and that leads to disability or death. ${ }^{6}$ The Act furthermore states that injuries are also considered to be work related when they take place during commuting to and from the job, or commuting between two jobs even if the employers are different. In this case, the event will be linked to the employer where the worker was heading to. Any injury leading to disability or death that affects a union leader while in union activities and duties will also be categorised as work related. Self-inflicted injuries are not included.

In 2012, the Ministry of Health issued the first comprehensive technical report on the mandatory notification system for severe and fatal work-related injuries. ${ }^{10}$ Before that, there were numerous regulatory norms but no integrated surveillance system. The National Occupational Health and Safety Information System was then created and the first actual data that the system reports are from $2014 .^{12}$ The main purpose of this system is to systematically register serious and fatal work-related injuries in a timely fashion in order to understand and identify risk factors and to implement preventive measures and access to healthcare services. ${ }^{10}$ The specific objectives include some of the following regarding occupational injuries: to investigate the causes, to determine epidemiological profiles, to assess risk factors and vulnerable worker groups (types of jobs, economic sectors, industries and activities) and to inform prevention programmes and enforcement policies.

The surveillance system begins with the detection and mandatory notification of a case to the corresponding health authority. The health authority immediately opens an enquiry and an individual work-related 'accident' notification (DIAT, Notificación Individual de Accidentes del Trabajo) entry is created within 24 hours of the event. The DIAT entry is then inputted into the National Occupational Health and Safety Information System (SISESAT) in a special module on fatal outcomes called the Registry on Fatal Work-related 'Accidents' (RALF, Registro de Accidentes Laborales Fatales) within 15 days. ${ }^{13}$ The registry data used in this study correspond to the RALF module.

\section{Data sources}

After signing a legal agreement between the investigator and the Superintendence of Social Security, access to the data contained in the Fatal Work-related Accident Registry (RALF) for 2014 and 2015 was granted. The data were provided digitally in Excel spreadsheet. All case data were anonymised.

The raw database contained 134 variables. After an initial review, 89 were discarded for the following reasons: no data in the fields, repeated data already picked up in other variable fields, variables concerned solely with administrative follow-up that did not answer the study question and many missing data. The resulting database contained 46 variables for the analyses. Of these, fields 
were cleaned and validated and secondary variables were obtained.

Contrary to initial expectation, the database that was provided did not contain all the information that the RALF module registers; notably, the text fields that describe the circumstances of the events and other qualitative information were not disclosed. Despite insistence, the authority did not grant access to any other descriptive data on fatal injuries.

\section{Variables}

Three variable domains that are included in the registry were used for the purpose of this study: variables concerning the companies where the fatal injury occurred, variables concerning the injured worker and variables concerning the event itself. Not all of the registry fields were included for characterisation as they did not contribute to answering the study question (eg, police officer involvement or presence of witnesses).

The companies are described in terms of number of workers, gender structure of the workforce, ownership (public or private), contracting status (main company, contractor, subcontractor, transient services), regulatory compliance with risk prevention departments (complies or not), health and safety programmes and workermanagement joint committees (have or do not have), labour law infractions in the previous 3 years (present or absent), compliance with notification procedures on occupational hazards and internal rules and regulations on safety in accordance with the law (complies or not), including implementation of corrective measures after injuries (number of corrective measures implemented).

Worker-associated variables were demographic (age and sex), International Standard Classification of Occupations (ISCO) code, whether manual worker or office worker, worker's municipality of residence, type of occupation (employer, dependent, self-employed, non-remunerated family member, volunteer), type of remuneration (fixed salary, variable income, honoraria), date of first contract, duration of contract (indefinite, fixed term, per project, seasonal), nationality and healthcare insurance system (public or private).

The variables associated to the event were the following: severity of the injury (fatal, serious and other), police officer involvement, witnesses, whether the injury occurred while in the workplace or commuting, if the injury occurred in the worker's usual workstation, date of occurrence of the event, date of death and whether at the time of the injury the worker was involved in usual tasks or had been assigned to out-of-the-ordinary tasks.

The registry includes many fields for the purpose of administrative follow-up that were excluded from the analysis. No descriptive text fields were provided so this study was not able to include any kind of qualitative characterisation of the events leading to the fatal injuries. No toxicological tests are included in this registry, nor are they routinely performed during case enquiries in Chile.

\section{Statistical analysis}

Results are reported with descriptive statistics appropriate for each type of variable: frequency distribution tables and statistics calculations. For the statistical analyses Excel 2013 and STATA V.12 (StataCorp, Texas) were used. No imputations were performed on the database.

\section{Ethics}

The accredited ethics committee of the Mutual de Seguridad approved the study which was communicated by decision letter dated 19 August 2015.

\section{Patient and public involvement}

No patients or public were involved in this study.

\section{RESULTS}

The cases included in this study were 401 occupational fatalities for 2014 and 414 for 2015, totalling 815 cases for the 2 years comprised in this study. The rate of fatal injuries per 100000 workers affiliated to the occupational social security system was calculated at 4.6 for 2014 and 4.4 for 2015, not including commuting injuries. This is also the rate that is officially reported by the statistical bulletins of the Social Security Superintendence. The overall mortality rate for all injuries, both at work and during commuting, per 100000 workers affiliated to the occupational social security system, was 7.2 for 2014 and 7.3 for 2015 .

\section{Worker characteristics}

Age is reported for 800 workers. The youngest was 17 at time of death, and the oldest was 85 years old. Median age was 43 and the IQR was 21. Ninety-two per cent of deaths occurred in men $(751 / 815)$ and $8 \%(64 / 815)$ in women. Regarding nationality, the study found that $98 \%$ (798/813) were Chilean, while the remaining $2 \%$ were distributed between Argentina (1), Bolivia (4), Colombia (1), Ecuador (1), Peru (7) and Spain (1). Only 293 workers had data for the type of health insurance coverage. Of these, $84 \%$ (247) belonged to the public health insurance system and the rest to the private system. The registry also reports the remuneration system that the workers had at the time of their death: $87 \%(705 / 813)$ had fixed salaries, while $13 \%(108 / 813)$ had variable income. In the two study years, there were no fatal cases of freelance workers. Table 1 summarises some of the primary characteristics of the fatal cases.

Sixty-three per cent (510) of work-related injuries resulting in death occurred in the workplace and $37 \%$ (305) occurred while commuting between home and work or between two jobs. In $64 \%$ (523) of the cases, the harmful event took place in the worker's usual workstation. Whether the worker was doing his usual tasks at the time of the fatal injury is also reported. On this item, $66 \%$ $(368 / 813)$ of workers were doing their usual work.

The Superintendence of Social Security qualifies injuries as severe when they lead to death (fatal), when 
Table 1 Sociodemographic and other characteristics of workers deceased from occupational injuries affiliated to the occupational health and safety social security system

\begin{tabular}{lrc}
\hline Age group (years) & $\mathbf{n = 8 0 0}$ & $\%$ \\
\hline$\leq 20$ & 17 & 2 \\
$21-30$ & 152 & 19 \\
$31-40$ & 171 & 21 \\
$41-50$ & 193 & 24 \\
$51-60$ & 169 & 21 \\
$61-70$ & 80 & 10 \\
$71-80$ & 17 & 2 \\
$\geq 81$ & 1 & 0 \\
\hline
\end{tabular}

\begin{tabular}{lrc}
\hline Gender & $\mathbf{n}=\mathbf{8 1 5}$ & $\%$ \\
\hline Female & 64 & 8 \\
Male & 751 & 92 \\
\hline Nationality & $\mathbf{n = 8 1 3}$ & $\%$ \\
\hline Chilean & 798 & 98
\end{tabular}

\begin{tabular}{lrc} 
Peruvian & 798 & 98 \\
Other & 8 & 1 \\
\hline Time with company (years) & $\mathbf{n = 7 3 7}$ & $\%$ \\
\hline$<1$ & 374 & 51 \\
$\geq 1$ to $<2$ & 108 & 15 \\
$\geq 2$ to $<3$ & 60 & 8 \\
$\geq 3$ to $<4$ & 34 & 5 \\
$\geq 4$ to $<5$ & 31 & 4 \\
$\geq 5$ to $<10$ & 72 & 10 \\
$\geq 10$ & 58 & 8
\end{tabular}

\begin{tabular}{lrc}
\hline Day of the week of injury & $\mathbf{n = 8 1 5}$ & $\%$ \\
\hline Monday & 146 & 18 \\
\hline Tuesday & 131 & 16 \\
Wednesday & 140 & 17 \\
Thursday & 143 & 18 \\
\hline Friday & 120 & 15 \\
Saturday & 89 & 11 \\
Sunday & 46 & 6 \\
\hline Commuting or at work & $\mathbf{n = 8 1 5}$ & $\%$ \\
\hline Commuting injury & 305 & 37 \\
Injury in the course of work & 510 & 63 \\
\hline At usual workstation or not & $\mathbf{n = 8 1 3}$ & $\%$ \\
\hline Usual workstation & 523 & 64 \\
\hline Not at usual workstation & 290 & 36 \\
\hline
\end{tabular}

resuscitation or rescue manoeuvres are performed, when there was a fall from height over $2 \mathrm{~m}$, when an immediate amputation occurs, when the event involves such a number of workers that it affects the operation of the site, or when two or more workers are affected with a common origin and place. The variable 'severity of injury' contains data on whether any of these conditions were met. Not all the injuries resulted in immediate death, but most did $(65 \%, 528 / 813)$. A large category with 220 cases was classified as 'other' and no information was provided on the nature of the event and resulting harms.

The RALF module registers the municipality where the fatal event took place, the municipality of the worker's home address and the municipality where the company headquarters are located. Regarding where the injury occurred, 229 out of 346 municipalities register work-related fatalities. In all, 20 municipalities report a frequency of over 20 deaths in both years.

Concerning the type of contract that the workers had, $79 \%$ (642/813) had indefinite contracts, while 13\% (102) had a fixed-term contract, $7 \%$ (57) had a contract for a specific job or task, and 1\% (12) had a seasonal contract. The date and hour of death is also registered for the study years. In six cases, the date of death is reported as prior to the injury, which is a clerical error. Of 809 valid fields, the event that causes the worker's death occurs on the same date as death in 712 cases $(88 \%)$. Of the remaining, death occurs between 1 and 225 days later.

From the registry, the study was also able to capture for how long the worker had been employed in the company before the fatal incident. Of the 815 cases, there are some that did not have any data associated or had clerical errors (eg, over 100 years). These errors appear in the 2014 registry but not in the 2015 one. Of the 737 cases that had valid data, $51 \%$ (374) had been employed in the company for less than 1 year.

The sectors with the greatest mortality rates are agriculture and fishing, mining, transport and construction. The Social Security Superintendence reported the activities differently for both years so it was not possible to aggregate the figures. The rates do not include fatalities during commuting. Table 2 shows the distribution of the deceased by industry per 100000 workers.

Regarding the economic activity that the worker was involved in, the registry reports data according to the National Classification of Economic Activities issued by the Chilean Internal Revenue Service. This study found that there are 211 activities in which at least one worker died from a work-related injury. Data are captured for 798 cases out of 815 . Of the 211 activities, 30 had two cases occurring in the two study years, and 110 activities had one deceased worker for this period. Consequently, there were 71 activities with three or more fatal cases (table 3).

The four activities that concentrate the greatest number of occupational deaths in the two study years were freight land transport, engineering works under construction, minor works under construction (contractors, masons, carpenters) and construction of complete buildings or parts of buildings. These four activities belong to two industries: transport (13.3\%) and construction $(17.5 \%)$. Together, they account for $31 \%$ of all of the cases of work-related fatal injuries in these 2 years. Workers of central government-includes the three branches of government but not the military or state 
Table 2 Mortality rate of work-related injuries by industry, by year, not including injuries occurring during commuting. $\mathrm{n}=485$

\begin{tabular}{|c|c|c|}
\hline Year & Industry & Rate \\
\hline \multirow[t]{8}{*}{2014} & Agriculture and fishing & 8.80 \\
\hline & Mining & 18.17 \\
\hline & Manufacturing industry & 3.75 \\
\hline & Electricity, gas and water & 6.11 \\
\hline & Construction & 7.97 \\
\hline & Retail & 2.68 \\
\hline & Transport and communications & 20.15 \\
\hline & Services & 0.82 \\
\hline \multirow[t]{15}{*}{2015} & $\begin{array}{l}\text { Agriculture, livestock, hunting and } \\
\text { forestry }\end{array}$ & 7.9 \\
\hline & Fishing & 11.3 \\
\hline & Exploitation of mines and quarries & 12.1 \\
\hline & Manufacturing industries & 3.6 \\
\hline & Power, gas and water utilities & 0.0 \\
\hline & Construction & 7.3 \\
\hline & Retail, vehicle repair and others & 2.4 \\
\hline & Hotels and restaurants & 2.9 \\
\hline & $\begin{array}{l}\text { Transport, storage and } \\
\text { communications }\end{array}$ & 17.0 \\
\hline & Financial services & 1.7 \\
\hline & $\begin{array}{l}\text { Real estate, business and rental } \\
\text { activities }\end{array}$ & 3.7 \\
\hline & Public administration and defence & 1.3 \\
\hline & Education & 0.3 \\
\hline & Social and health services & 0.9 \\
\hline & $\begin{array}{l}\text { Other personal, social and community } \\
\text { services }\end{array}$ & 1.7 \\
\hline
\end{tabular}

Adapted from the 2015 Statistical Bulletin of the Chilean Social Security Superintendence.

universities-also concentrated a high number of deaths: 15 in 2 years mostly during commuting.

\section{Company characteristics}

In Chile, companies are classified according to the number of workers. Accordingly, a microenterprise has one to nine workers, a small enterprise has between 10 and 49 workers, a medium-sized company has from 50 to 199 workers and a large company has over 200 workers. Of the 810 cases in which the RALF module provides the number of workers for the involved companies, the study found that $72 \%$ of the cases occurred in small and medium-sized enterprises and only $28 \%$ in large companies (table 4).

According to Chilean law, companies with over 100 employees must conduct preventive activities in the workplace and there should be a risk prevention department. The study found that $50 \%$ of the companies that should
Table 3 Distribution of cases by economic activity involving 10 or more fatal cases for 2014 and 2015, by injury occurring at work or during commuting. $n=798$

\begin{tabular}{|c|c|c|c|c|}
\hline & & & Work & Commuting \\
\hline Economic activity & $\mathbf{n}$ & $\%$ & $\%$ & $\%$ \\
\hline $\begin{array}{l}\text { Freight transport by } \\
\text { road }\end{array}$ & 106 & 13.3 & 89.6 & 10.4 \\
\hline $\begin{array}{l}\text { Engineering works } \\
\text { under construction }\end{array}$ & 53 & 6.6 & 67.9 & 32.1 \\
\hline $\begin{array}{l}\text { Minor works under } \\
\text { construction } \\
\text { (contractors, } \\
\text { masons, carpenters) }\end{array}$ & 49 & 6.1 & 67.3 & 32.7 \\
\hline $\begin{array}{l}\text { Construction of } \\
\text { complete buildings } \\
\text { or parts of buildings }\end{array}$ & 38 & 4.8 & 55.3 & 44.7 \\
\hline $\begin{array}{l}\text { The rest of the other } \\
\text { business activities } \\
\text { npc }\end{array}$ & 23 & 2.9 & 47.8 & 52.2 \\
\hline $\begin{array}{l}\text { Urban transport } \\
\text { via bus (public } \\
\text { transportation) }\end{array}$ & 15 & 1.9 & 86.7 & 13.3 \\
\hline Central government* & 15 & 1.9 & 33.3 & 66.7 \\
\hline $\begin{array}{l}\text { Site preparation, } \\
\text { excavation and } \\
\text { earthworks }\end{array}$ & 13 & 1.6 & 53.8 & 46.2 \\
\hline
\end{tabular}

$\begin{array}{llllr}\text { Copper extraction } & 12 & 1.5 & 91.7 & 8.3 \\ \begin{array}{l}\text { Other personal } \\ \text { service activities }\end{array} & 12 & 1.5 & 50.0 & 50.0 \\ \text { npc } & & & & \end{array}$

$\begin{array}{lllll}\begin{array}{l}\text { Cultivation of fruit } \\ \text { trees in trees or } \\ \text { shrubs with a life }\end{array} & 12 & 1.5 & 33.3 & 66.7 \\ \begin{array}{l}\text { cycle greater than } \\ \text { one season }\end{array} & & & & \\ \begin{array}{l}\text { Wholesale of other } \\ \text { products }\end{array} & 12 & 1.5 & 75.0 & 25.0 \\ \end{array}$

*Includes workers belonging to the three powers of government: judiciary, executive and legislative. Does not include military or state universities.

npc, not previously classified.

have a risk prevention department $(278 / 555)$ did not have one at the time of the fatal injury.

The registry also reports on whether there was a joint committee on hygiene and safety where the event occurred. Joint committees are mandatory in companies with 15 or

\begin{tabular}{ll}
\hline Table 4 & Distribution of cases by company size. $\mathrm{n}=810$ \\
\hline Company size & $\mathbf{n}(\%)$ \\
\hline Large & $233(29)$ \\
Medium & $143(18)$ \\
Small & $206(25)$ \\
Micro & $228(28)$
\end{tabular}




\begin{tabular}{ll}
$\begin{array}{l}\text { Table } 5 \\
\text { more fatalities }\end{array}$ & $\mathbf{n}$ \\
\hline Occupations according to ISCO & 168 \\
\hline Elementary workers not elsewhere classified & 73 \\
Heavy truck and lorry drivers & 38 \\
Odd job persons & 22 \\
Security guards & 18 \\
Production clerks & 18 \\
Building frame and related trade workers not & \\
elsewhere classified & 14 \\
Bus and tram driver & 11 \\
Crop farm labourer & 11 \\
Subsistence crop farmers & 11 \\
Traditional chiefs and heads of village & 10 \\
Business services and administration \\
managers not elsewhere classified
\end{tabular}

ISCO, International Standard Classification of Occupations.

more workers, are formed by representatives from the workers and from management, and are responsible for detecting and evaluating risks for injuries and professional diseases. In $31 \%$ of the companies that had a work-related injury resulting in death, there was a joint committee (174/555), $48 \%$ reported not having one (268/555) and 113 companies were not required by law to have one. In other words, of the 442 companies with registered data that must have a joint committee, $60 \%$ did not have one at the time of the event. The registry also shows that $24 \%$ (122) of the companies did not apply corrective measures after the incident and 23\% (119) did. Most of the companies (89\%) applied 10 or less corrective measures.

One of the registry fields reports on whether the employer had previously been fined for regulatory non-compliance. The results show that 22\% (121/555) of companies had been previously fined. Similarly, $27 \%$ $(148 / 555)$ of the employers did not report occupational hazards according to Chilean law, while $75 \%(419 / 555)$ of the companies had a compliant version of the internal hygiene and safety regulations manual.

Of the 815 cases for 2014 and 2015, a correct occupation was registered for 648 cases. However, 102 cases had to be excluded from the analysis as they all had the same ISCO code number (3141), which is clearly a clerical error. Furthermore, there are 65 cases in which no occupation was registered. Table 5 shows the 11 occupations that have 10 or more deceased workers during the study period. Heavy truck and lorry drivers account for an important number of deaths (73), as well as bus and tram drivers (14). Security guards are also exposed to high fatality rates, with 22 cases in the 2 years of the study.

\section{DISCUSSION}

This is the first study conducted in Chile using data from the national mandatory registry for occupational deaths notified for 2014 and 2015 and reports overall occupational mortality rates for both years-on the job and commuting fatalities. The study characterises the cases using many variables contained in the national registry for occupational deaths, especially taking into account data on health and safety occupational national regulations, which have not been previously reported. This study found that nearly three out of every four fatal cases occur in small and medium-sized enterprises, that $63 \%$ of the cases occur on the job and not during commuting, and that little over a half of all fatal injuries occurred in workers who had been employed for less than a year in their company. The sectors with the greatest mortality rates are agriculture and fishing, mining, transport and construction. Importantly, most of the companies that had a fatal injury case during the two study years did not have a risk prevention department, did not have an occupational safety joint committee, and some had been previously fined, indicating an overall laxity with regard to regulatory compliance.

The RALF module became part of the national social security information system on work-related injuries and occupational exposures as an online registry only in 2011. It is now mandatory for the workers' health and safety organisations to immediately notify the occurrence of any kind of work-related injury leading to a fatal outcome. ${ }^{14}$ While the implementation of this policy is important, the system still has many shortcomings that hindered the analysis of the circumstances in which the fatal events occurred. Some of these shortcomings are incomplete data, different fields for the two study years, clerical errors, lack of comparability with databases used in other countries for occupational surveillance and many occupations registered with non-specific or incorrect codes, making further characterisation impossible.

Moreover, it was not possible to cross data with other national databases as only anonymised data were provided. Chile has a single identifying number for every person in the country, either foreign or national, but this information was not provided. Consequently, it was not possible to cross information with the health or labour agencies' inquiries on the fatal cases, both of which contain important qualitative detail. Other data sources that could have been included are death certificates, clinical records and histories, autopsy reports and toxicological analyses. The fact that Chile does not centralise this information limits the ability to ascertain if the workers had been exposed to psychotropic substances or other toxic elements before the event. Unfortunately, this type of investigation is not regularly conducted in Chile in the case of fatal work-related injuries.

The RALF module used in this study purportedly contains text fields that describe the mechanism of injury and other information on intervening circumstances. However, these fields were omitted from the database that was provided for the study and since registries are confidential, it was not possible to verify what the registry actually contains, and what could have been 
useful for epidemiological analysis. In addition, the database contains several variables that do not specifically address the events, but are focused on the administrative follow-up of the cases. Some of these variables do shed light on the degree of compliance of companies with regulatory norms, which could be correlated with a greater (or lesser) injury rate.

However, for the purpose of extracting information from an existing registry in order to formulate hypotheses on factors associated with fatal events in the workplace, the present study provides valuable input on preventable risk factors, especially when considering management practices, workplace organisation, compliance with existing rules and regulations or other sociodemographic characteristics.

According to international studies that have estimated the frequency of work-related deaths, the incidence of fatal occupational injuries fluctuates between 0.8 and 21.9 per 100000 workers. ${ }^{15-31}$ For Chile, one study reported a rate of $15.4 / 100000$ worker fatalities in 2003. ${ }^{21}$ According to the findings of the present study, Chile's mortality rate from work-related injuries, including commuting injuries, is 7.2/100 000 workers for 2014, and 7.3/100 000 workers for 2015 . This rate is higher than that reported in other countries such as Germany $(2.5 / 100$ 000; 2003) and Finland $(2.1 / 100000 ; 2003$, not reported whether commuting injuries are excluded or not), ${ }^{21}$ or in Australia (1.9/100 000; 2009-2010, includes commuter fatalities). ${ }^{32}$ On the other hand, rates reported for countries similar to Chile are consistently higher, such as Argentina (14.9/100 000; 2003), Bolivia (19.6/100 000; 2003) or Brazil (16.1/100 $000 ; 2003$ ) according to the same study on global trends. ${ }^{21}$

The analysis of worker fatality from occupational injuries in Chile in 2014 and 2015 reveals that more workers die from incidents on the job than during commuting. This is consistent with a New South Wales, Australia, study that reported that for the 1989-1992 period, $78.3 \%$ of all fatalities were work-related versus $21.7 \%$ that occurred during commuting. ${ }^{33}$ Another study from France for the 2002-2004 period reported that $44 \%$ of fatal injuries occurred while commuting to work. ${ }^{19}$

Several studies describe the frequency of work-related deaths according to economic sectors or activities. A study from California ${ }^{34}$ reports that the economic activities with the greatest number of occupational deaths were the petroleum industry $(51.4 / 100000)$, followed by transport (23.6/100 000), government $(21.5 / 100000)$, agriculture (18.6/100 000) and construction (14.4/100 $000)$. A study from Taiwan reports that the sectors with the greatest frequency of work-related fatalities were agriculture, forestry and fishing. ${ }^{20}$ In the case of Chile, this study found that the industries that concentrated a larger number of fatalities were transport and communications $(20.2 / 100000)$, mining $(18.2 / 100000)$, agriculture and fishing (8.8/100 000), construction $(8 / 100000)$ and power/gas/water utilities $(6.11 / 100000)$.

The comparison of rates between countries is particularly difficult because each country reports differently.
Some countries include fatal injuries while commuting, or deaths from exposure to hazardous substances and other fatal conditions. Sadly, many countries do not even have national statistics on occupational fatalities. ${ }^{11}$ There is consensus that proper inquiries into the causes of harmful events in the workplace is essential to obtain useful information to help prevent injuries from happening and that the enquiries often lack detail and depth in determining what caused the incidents, which must also include company management and organisation systems. ${ }^{35}$ These observations are consistent with the findings of this study on the quality of the Chilean registry. The registries on work-related fatal injuries in Chile were set up to follow-up on the entitlements of workers and their families, but not necessarily to provide insight into the epidemiology of the problem.

There are very little data on the incidence of fatal occupational injuries in the informal sector, as under-reporting is a critical problem ${ }^{11}$ even when these kinds of jobs are associated with a higher incidence of fatal outcomes compared with formal occupations. ${ }^{36}$ Informal jobs are also related to lower training levels of its workers and reduced levels of enforcement of social security laws. Human development indicators also play out in how a country values and protects the health of its workers. Poor workers generally have lower educational levels and this will lead to employment in less qualified jobs, which in turn is associated with a higher risk of work-related injuries and professional diseases. ${ }^{37}$

\section{CONCLUSIONS}

This study, while descriptive, provides valuable insight into the current national registry on occupational deaths in Chile. More specifically, some of the variables that are currently picked up from mandatory notifications of fatal occupational cases on working and employment conditions, and economic sectors and organisation characteristics, could be useful to establish associations with the occurrence of a fatal occupational injury. Those implicated variables should be analysed with regression models to estimate the strength of the association with fatal outcomes. To do so, we would need the complete work-related injury database, including those with and without fatal outcome. This approach could help develop a risk prediction model that would include factors that are strongly associated with serious and fatal injuries, thus also setting the basis for preventive policies geared towards monitoring more intensely those factors.

In order to better understand the circumstances associated with fatal outcomes from work-related injuries, we need to have integrated and internationally equivalent electronic records. Accurate and timely information must be collected from several perspectives, including the description of the mechanism that caused the injury and harm, autopsy records, toxicological exams and comprehensive data on the workers and the companies. Although Chile has made large inroads in improving 
the lot of workers in recent decades, much still has to be done to achieve a proper epidemiological integration of the surveillance data needed to input into risk prediction models from a public health perspective.

Acknowledgements The author thanks Dr Juan José Orellana, her thesis tutor, and Dr Sergio Muñoz, Dr Ximena Osses and Dr Roxana Gayoso for their valuable input and feedback. The author also thanks Vicerrectoría de Investigación, Desarrollo e Innovación and the Dirección de Investigación Científica y Tecnológica of the Universidad de Santiago de Chile (VRIDEI-DICYT-U de Santiago) for their support in helping to translate the manuscript.

Contributors VCB is the sole author of this manuscript. The manuscript is the result of her thesis research project.

Funding This work was supported by Mutual de Seguridad of the Chilean Chamber of Construction. The funds are Act No 16.744-sourced, which mandates that worker's occupational health prevention organisations must invest in investigation and development. The Chilean Social Security Superintendence oversees the allocation of funds, aligned with nationally established priorities.

Competing interests VCB has conducted other research projects for the occupational safety and health authorities in the past 3 years on different aspects of worker health and safety.

Patient consent Not required.

Ethics approval Comité de Ética de la Mutual de Seguridad de la Cámara Chilena de la Construcción.

Provenance and peer review Not commissioned; externally peer reviewed.

Data sharing statement Data set, codebook and ethics committee approval letter are available at Figshare repository (D0l: https://doi.org/10.6084/m9.figshare. 5371519).

Open access This is an Open Access article distributed in accordance with the Creative Commons Attribution Non Commercial (CC BY-NC 4.0) license, which permits others to distribute, remix, adapt, build upon this work non-commercially, and license their derivative works on different terms, provided the original work is properly cited and the use is non-commercial. See: http://creativecommons.org/ licenses/by-nc/4.0/

Open data All data have been made publicly available and can be accessed at https://doi.org/10.6084/m9.figshare.5371519.

(c) Article author(s) (or their employer(s) unless otherwise stated in the text of the article) 2018. All rights reserved. No commercial use is permitted unless otherwise expressly granted.

\section{REFERENCES}

1. International Labour Organization. ILO Flagship Programme Global Action for Prevention on Occupational Safety and Health (OSH-GAP) Brochure.

2. Ryder G. The International Labour Office. International newsletter on occupational health and safety. 2018.

3. ILO estimates over 1 million work-related fatalities each year. 2018 http://www.ilo.org/global/about-the-ilo/newsroom/news/WCMS_ 007969/lang--en/index.htm (accessed 01 Feb 2018).

4. Ratifications of ILO conventions: ratifications by convention. 2018 http://www.ilo.org/dyn/normlex/en/f?p=NORMLEXPUB:11300:0: NO::P11300 INSTRUMENT ID:312300 (accessed 01 Feb 2018).

5. SUSESO: Atención de usuarios - ¿Qué trabajadores están cubiertos por este seguro Ley $\mathrm{N}^{\circ} 16.744$ ? $2018 \mathrm{http}: / /$ www.suseso.cl/606/w3article-18614.html (accessed 01 Feb 2018).

6. H. Congreso Nacional. Ley-16744 01-feb-1968 Ministerio del Trabajo y Previsión Social, Subsecretaría de Previsión Social - Ley Chile Biblioteca del Congreso Nacional. (1968).

7. Superintendencia de Seguridad Social. Informe anual 2014 Estadísticas sobre Seguridad y Salud en el Trabajo. 2015

8. Superintendencia de Seguridad Social. Informe anual 2015 Estadísticas sobre Seguridad y Salud en el Trabajo. 2016.
9. The World Bank. Labor force, total | Data. $2017 \mathrm{https} / / /$ data. worldbank.org/indicator/SL.TLF.TOTL.IN (accessed 01 Feb 2018).

10. Ministerio de Salud. Norma Técnica para la Implementación de Sistema de Vigilancia de Accidentes de Trabajo con Resultado de Muerte y Graves. 2013.

11. International Labour Office. Estimating the economic costs of occupational injuries and illnesses in developing countries: essential information for decision-makers. 2012.

12. Ministerio de Salud de Chile. SINAISO - Sistema Nacional de Información en Salud Ocupacional. http://www.sinaiso.cl/Default. aspx\# (accessed 02 Feb 2018).

13. Calificación de accidentes del trabajo. Imparte instrucciones a los organismos administradores del seguro de la Ley $N^{\circ} 16.744$. Deroga Circular 1.967, de 2002. 2017 http://sistema.suseso.cl/Produccion/ jurisprudencia252.nsf/Normativa_F.xsp?action=openDocument\& documentld=A28A6 (accessed 02 Feb 2018).

14. Superintendencia de Seguridad Social. Circular 2611: Notificación de accidentes laborales fatales de trabajadores de entidades empleadoras adheridas a las mutualidades de empleadores. 2010.

15. Abas AB, Mohd Said DA, Aziz Mohammed MA, et al. Fatal occupational injuries among non-governmental employees in Malaysia. Am J Ind Med 2013;56:65-76.

16. McNeilly B, Ibrahim JE, Bugeja $L$, et al. The prevalence of workrelated deaths associated with alcohol and drugs in Victoria, Australia, 2001-6. Inj Prev 2010;16:423-8.

17. Day ER, Lefkowitz DK, Marshall EG, et al. Utilizing United States Coast Guard data to calculate incidence rates and identify risk factors for occupational fishing injuries in New Jersey. $J$ Agromedicine 2010;15:357-62.

18. Centers for Disease Control and Prevention (CDC). Commercial fishing fatalities-California, Oregon, and Washington, 2000-2006. MMWR Morb Mortal Wkly Rep 2008;57:426-9.

19. Brière J, Chevalier A, Imbernon E. Surveillance of fatal occupational injuries in France: 2002-2004. Am J Ind Med 2010;53:1109-18.

20. Ho SC, Wang LY, Ho CK, et al. Fatal occupational injuries in Taiwan, 1994-2005. Occup Environ Med 2010;67:251-5.

21. Hämäläinen $P$, Leena Saarela K, Takala J. Global trend according to estimated number of occupational accidents and fatal work-related diseases at region and country level. J Safety Res 2009;40:125-39.

22. Centers for Disease Control and Prevention (CDC). Work-related injury deaths among hispanics--United States, 1992-2006. MMWR Morb Mortal Wkly Rep 2008;57:597-600.

23. Mulloy KB, Moraga-McHaley S, Crandall C, et al. Occupational injury mortality: New Mexico 1998-2002. Am J Ind Med 2007;50:910-20.

24. Centers for Disease Control and Prevention (CDC). Fatal occupational injuries-United States, 2005. MMWR Morb Mortal Wkly Rep 2007;56:297-301.

25. Cohen MA, Clark RE, Silverstein B, et al. Work-related deaths in Washington State, 1998-2002. J Safety Res 2006;37:307-19.

26. Ahn YS, Bena JF, Bailer AJ. Comparison of unintentional fatal occupational injuries in the Republic of Korea and the United States. Inj Prev 2004;10:199-205.

27. John Bailer A, Bena JF, Stayner LT, et al. External cause-specific summaries of occupational fatal injuries. Part I: an analysis of rates. Am J Ind Med 2003:43:237-50.

28. Loomis D, Bena JF, Bailer AJ. Diversity of trends in occupational injury mortality in the United States, 1980-96. Inj Prev 2003;9:9-14.

29. Santamaría N, Catot N, Benavides FG. Tendencias temporales de las lesiones mortales (traumáticas) por accidente de trabajo en España (1992-2002). Gac Sanit 2006;20:280-6.

30. Lin YH, Chen CY, Luo JL. Gender and age distribution of occupational fatalities in Taiwan. Accid Anal Prev 2008;40:1604-10.

31. Jin K, Courtney TK. Work-related fatalities in the People's Republic of China. J Occup Environ Hyg 2009;6:446-53.

32. Safe Work Australia. Work-related traumatic injury fatalities, Australia 2009-10. 2012.

33. Driscoll T, Mitchell R. Fatal work injuries in New South Wales. NS W Public Health Bull 2002;13:95-9.

34. Cone JE, Daponte A, Makofsky D, et al. Fatal injuries at work in California. J Occup Med 1991;33:813-7.

35. Salguero-Caparros F, Suarez-Cebador M, Rubio-Romero JC. Analysis of investigation reports on occupational accidents. Saf Sci 2015;72:329-36.

36. Santana VS. Empleo, condiciones de trabajo y salud. Salud Colect 2012;8:101-6.

37. Borrell C, Muntaner C, Benach J, et al. Social class and self-reported health status among men and women: what is the role of work organisation, household material standards and household labour? Soc Sci Med 2004;58:1869-87. 